\title{
A Khan Framework-Based Approach to Successful MOOCs Integration in the Academic Context
}

\author{
https://doi.org/10.3991/ijet.v15i12.12929
}

\author{
Aicha Marrhich ${ }^{(凶)}$, Ichrak Lafram, Naoual Berbiche, Jamila El Alami \\ Mohamed V University, Rabat, Morocco \\ aichamarrhicheresearch.emi.ac.ma
}

\begin{abstract}
Massive open online courses (MOOCs) expansion encounter many challenges related to different aspects, from learner's perspective to teacher's perspective, to technological aspects. Previous studies demonstrated the prevailing challenges pertaining to Academic contexts using both qualitative analysis and quantitative analysis of different samples from different countries. In our study, we have tried to look at practices from all over the world regarding MOOCs implementation, we presented a summary of the major challenges of MOOCs as well as their strengths vis a vis the open education in both general and academic contexts. Following the steps of Khan's framework for online learning, our ultimate objective was to come up with an approach that can bridge the challenges that hinder current effective delivery of MOOCs and calls for metrics that respect the results of previous work in the implementation of blended learning in the Academic context.
\end{abstract}

Keywords-Blended learning, MOOCs, integration, Academic context, challenges, benefits, khan framework

\section{Introduction}

\subsection{The Emergence of MOOCS}

The advent of digital technology has accelerated the pace of change. MOOCs are an example of this evolving technology and also a continuity of the movement of open education[1], [2]. For so many years, researchers and instructors have been intrigued with the contribution of technology to help education gain wide access and grow to reach the whole nations. Today the internet can be used to deliver content. One of the segments that have gained popularity with the rise of technology is Massive Open Online Course. MOOCs proponents are certain that they can enhance higher education standards and practices. Innovators in high education perceive a big potential in MOOCs. MOOCs particularity resides in the fact that they suggest another way of learning as they target the big mass, they rely on peer to peer centered learning rather than traditional lecturer centered approach. Millions of students from all over the world can enroll, they pay no tuition or may pay a fee for a completion 
certificate, and everyone takes the same class offered by prestigious universities in partnership with MOOC providers such as Coursera, Udx, Udemy, Udacity, etc.

\subsection{Research context}

In 2016, Morocco decided to adopt a plan called Digital Morocco 2020. The main objectives of this plan focus on the development of education and the acceleration of the digital transformation and to address problems of governance and digital competencies. For this purpose, big financial resources were allocated to implement the different measures, mainly to invest in telecom infrastructure, in the acceleration of equitable access to broadband and very high speed, and to reduce the digital divide for the benefit of citizens (connectivity for all, primary, secondary and higher education, public access to WIFI).

A recent study about MOOCs in Moroccan higher education justified a MOOC approach to Higher education in Morocco [3]. Cadi Ayyad University of Marrakech is a pioneer and leader in MOOCs both in Morocco and Africa. Since 2013, the university started making its own courses and made them accessible online to students. In 2014, The number of students enrolled raised by 32\% from 38000 to 56000 , this means that Moroccans are interested in new ways of learning that respond to technological advancement. Since learners have different learning styles, blended learning remains a better solution so as to cater for these requirements. MOOCs can thus enhance face to face courses.[3]

Also, many countries today have many reasons to opt for blended learning in order to alleviate some of the problems that high education is facing:

- Great demand on universities that exceeds universities capacities

- Expand education reach in rural areas in order to reduce face time

- Shortage of well-trained teachers

- Opening the field of new opportunities for youth to develop international competencies

- Catching up with the digital development tendencies in the world

\subsection{Research purpose}

This paper aims first at gaining a better understanding of the advantages and disadvantages of MOOCs on a global scale in a general context. The focus will then shift to the look at the benefits and hindrances reported in previous studies that aimed to integrate MOOCs in Academic contexts and ultimately to the proposition of an approach for blended learning integration in Academic contexts that take into consideration all the relevant challenges pertaining to the literature review. Our objective is to try to explore the features of MOOCs that lead to better student outcomes in order to design an approach that holds key factors to a successful blended learning implementation experience in the Academic context.

In the broadest sense, our study is motivated by investigating practices of MOOCs and blended learning experiences in other institutions, motivations, benefits, 
challenges and barriers to overcome and to identify the role of different stakeholders in blended learning.

\section{$2 \quad$ Literature Review}

\subsection{A growing interest for MOOCS benefits}

In this section, we summarize previous works pertaining to the advantages of MOOCs. MOOCs are considered as a very important educational approach with a big impact on the future of online learning.

Many virtues lie within MOOCs and promote their adoption by members around the world. One of the motives that encourage learners to enroll is that MOOCs are developed by elite universities and their respective prominent professors[4], enrolling in a MOOC gives you the prestigious feeling of belonging to these elite universities. Also, MOOCs can allow for enormous enrollment engaging large numbers of students [5], MOOCs are perceived as the ultimate solution to alleviate the barriers to education around the world. From the same perspective, it has been stipulated that MOOCs contribute to overcoming the physical and financial barriers [5] that students have in a way that anyone in the world can enroll for free. MOOCs allow for minimal costs with great learning opportunities and thus make learning possible irrespective of location or financial parameters.

Furthermore, there's a study [6] that tried to approach motivation for MOOCs from a learner's point of view, findings revealed that MOOCs that cover similar subjects can help students grasp in-class content quickly, For instance the Java programming for beginners' Udacity MOOC helped students fully understand the programming concept and feel comfortable with advanced class content. Sometimes, the school programs scheduled in classes cannot cover all the spectrum of a particular field, MOOCs therefore contribute to expanding students' perspective by viewing complementary content online [6]. Several studies have explored the overall of online learning experience satisfaction, Janet W.H. Sit* et al. used a survey to examine student's experience in online learning within a part-time post-registration baccalaureate nursing degree programme to 198 students. Findings revealed that the most frequently identified benefit of online learning was flexibility in the learning process, online learning experience was time saving[7]. Vanderbilt university embedded a machine learning MOOC from Coursera[8]. Students feedback was positive as they were very content to be able to learn at their own pace.

To wrap up, it becomes obvious that the strongest point about MOOCs for learners lies within their flexibility. Since most courses are offered in a self-paced format or on a regular schedule with new sessions starting on a weekly basis, students reported that being able to study at their own pace made it easier for them to catch up and to adjust their timetables so as to keep up with course progress. 


\subsection{MOOCS problems on a global scale}

A lot of studies have attested MOOCs to have many challenges, the Janet W.H. Sit* et al. study identified also a learning hindrance with the online learning, similar to the findings from the questionnaire portion of study, $36 \%$ of students claimed the inadequate opportunity for human contact and interaction, the length of the course material was reported by $23 \%$ of respondents [7]. In 2013, Siemens[9] revealed that one of the major most alarming problems of MOOCs is the poor completion rates. Students struggle to complete MOOCs they are enrolled in even though MOOCs can propose a flexible studying pace. Siemens also highlighted [9] in his study that MOOCS risk deskilling the professorate as MOOCs offered in platforms threaten to reduce numerous teaching jobs.

Schmidt et al. [8]in their experience about implementing a MOOC declared that it requires enormous amount of time to prepare content prior to MOOC launch, filming videos than the accustomed used to face to face courses, the development of student evaluation mechanisms and the heavy involvement in the forums discussions to dispel common mistakes and deal with knowledge gaps among students

Another big challenge is cheating and plagiarism, so effective assessment remains a big challenge [10]. Since online exams are not supervised by invigilators whom the role consists of controlling and monitoring the flow of exams. In their study, Bawarith et al. listed the different types of cheating in traditional exams compared to online exams. In both traditional and online contexts, students can use cheating sheets, in small fonts hidden in clothes or under watch [11], they can also use prewritten sheets hidden in books or under folders below the desk, they can use numeric devices to communicate answers via cellphones or ipods having recording abilities with earphone wires. In addition, in online environment, there are other forms such as taking exams for another person, using applications that help solve exam questions, copying test questions and sending back to an expert to send back answers, using knowledge resources from the internet such as an e-book.

In 2014, Chen [10] pointed out other problems pertaining to MOOCs, he stipulated that there is a lack of interaction between instructor and learners, he also questioned the copyright ownership of MOOCs since these are often multifaceted as they regroup many stakeholders. In addition, Chen referred to another hindrance to MOOCs that lies in limited access to internet in some countries, because MOOCs are made out of lectures in video format that require high internet bandwidth.

North et al. shed light on another facet of MOOCs challenges[5], MOOCs don't allow for individual interaction or feedback from an expert, learners have a feeling of isolation while studying. In spite of MOOCs platform opportunities for discussion in forums, the feeling of isolation prevails, they also go back to the idea of completion rates that are very low and plagiarism and cheating being widespread common problems of MOOCs. Sinclair revealed in his work [12] that MOOCs come with a double edged ending, we have seen earlier that MOOCs can provide an autonomous way to learning, however students declared they faced difficulties to find the right learning paths and to understand the material. Sinclair highlighted also the underlying 
cost of MOOCs as their main component which is based on video lectures require high quality production norms and there is very limited if any return on investment.

In some cases, it has been revealed [13] that student's personal motivation is a determinant key factor for low dropout rates, the motivation can drop low when students have insufficient prior knowledge about the topic, they feel overwhelmed with new complex information and fail to understand the content leading them to abandon the course.

Romero and Ventura [14] stipulate that the 10000 to 1 student-teacher ratio offered by MOOCs makes it impossible for student individual feedback.

Another relevant drawback that cast doubt on the bright contribution of MOOCs to education was underlined by Carlson \& Blumerstyk, in fact, they stipulated that there are some courses focused on communication skills or business etiquette that can only be acquired and fostered through face to face tuition, MOOCs may not be able to empower them.

To the landscape of hindrances that stand in the way of MOOCs expansion, it is worthy to add one parameter which is the learner's digital competencies

and the digital autonomy needed in a MOOC, which are sine qua none skills to maneuver MOOCs platforms.

Furthermore, a recent study [15] aimed at understanding student engagement based on the analysis of student's feedback in 18 highly rated MOOCs revealed that low teaching involvement during delivery stage, students value instructor's enthusiasm and good humor, also course content based on real world application and problem solving were more engaging and preferable over mere exposition of information. In addition to that, teachers who provided interaction strategies gained more interaction such as giving opportunities for students to interact with peers relating to their submitted assignements without posting explicit answers and organizing live online sessions for further explanations or holding one hour virtual every week to answer students' questions using help scout to manage students' mails requests.

The findings of this study highlighted the importance of customization of content to learners' differences. Indeed, the way in which an individual perceives, processes information is determinant in the learning process. According to Felder Silverman Learning style model (FLSM), there are four dimensions that intervene in the learning process of individuals. Perception (sensory, Intuitive), Input(Visual, Verbal), Processing (Active, reflective), understanding (sequential, global)[16]. Another learning style model is the kolb's model, which based on four stages: the concrete experience, the reflective observation, the conceptualization and the active experimentation[17]. A recent study has underlined the usefulness of designing personalized MOOC according to the needs and abilities of the learner.[18]

One big challenge of MOOCs is to provide relevant content to the learner depending on his learning style.

The problems that MOOCs face can be split into four categories which are challenges perceived from the learner's perspective, from the teacher's perspective and from organizational perspective and from MOOC characteristics. 
Table 1. Advantages and drawbacks of moocs on a global scale

\begin{tabular}{|c|c|}
\hline Advantages & Drawbacks \\
\hline $\begin{array}{l}\text { Getting certificates from elite } \\
\text { universities } \\
\text { Demolishing the financial } \\
\text { and geographical barrier that } \\
\text { stands in the way of } \\
\text { education } \\
\text { Having a flexible learning } \\
\text { pace } \\
\text { Encouraging student's } \\
\text { autonomy }\end{array}$ & $\begin{array}{l}\text { Learner's perspective } \\
\text { Lack of interaction between learners and the instructor } \\
\text { Having insufficient prior knowledge about the topic } \\
\text { MOOCs characteristics } \\
\text { Failure to understand the content and the material } \\
\text { No possible individual mentoring and feedback } \\
\text { Plagiarism and cheating } \\
\text { High dropout rates } \\
\text { Different learning styles } \\
\text { Teacher's perspective } \\
\text { Instructor work overload } \\
\text { Effective assessment } \\
\text { Organizational perspective } \\
\text { No return on investment } \\
\text { Copyright ownership } \\
\text { Limited access to the internet } \\
\text { The cost of producing high quality content is high }\end{array}$ \\
\hline
\end{tabular}

\section{Blended learning in the Academic context}

\subsection{Blended learning}

Garrison and Kanuka [19] defined blended learning as a perfect combination of online and face-to-face learning, indeed blended learning aims to lower face to face interaction and replace it with online learning. It is worthwhile to note the difference between the two words "e-learning" and "blended learning", since the first is a web based only learning while the second includes some face to face learning.

\subsection{Benefits of MOOCs integration in the academic context}

Until today, there are a number of universities that have explored, implemented and evaluated MOOCs integration in their formal education. This paper will focus on universities that have embedded content from MOOCs as a supplementation or a replacement of segments of academic courses.

The growing popularity of MOOCs in universities is conspicuous. The MOOCs expansion raised many questions in the field of education. Can we incorporate MOOCs in our traditional classrooms? If MOOCs can be embodied in our universities, what benefits can we draw on this blended learning approach? Many studies tried to answer these questions. Today, integrating MOOCs in traditional education has been explored in many countries. Griffiths studied the experience of blended learning in the University of Maryland in the USA to question MOOCs 
ability to improve students' outcomes and reduce costs for students enrolled in traditional institutions. 15 tests concerning hybrid courses that include MOOCS with consent of coursera to use content in these tests were conducted[20]. For instance, the San José State University incorporated the edx MOOC MITx6.00 Circuits and Electronics into his EE98 Introduction to Circuits Anlysis course and devoted classroom time to group activities, projects with quizzes to assess his students' progress[21]. The study compared results from a blended section of Electrical Engineering with three traditional sections, the results were very encouraging because the entire class grades in the blended class were $10 \%$ points higher compared to traditional sections both for the first and the second midterm and weak students in class performed better. This program reached $90 \%$ success rate compared with $55 \%$ in the traditional settings, Ghadiri et al. concluded in this case study that using MOOCs can be very positive with challenging subjects and courses, the flipped classroom approach empowers student engagement, student retention and reduces student failure rate.

\subsection{Challenges of MOOCs integration in the academic context}

In India, Chatterjee and Nath [22] evaluated factors haunting large scale implementation of MOOCs in the Indian context, the main findings rely on the need for a national entity to be set up that would oversee the overall implementation and would stand as guarantor for good functioning of blended learning. In a study conducted by Birch et Burnett[23], they analyzed the context that contributed to the evolving of distance education learning. The study sheds light on the hindrances that impede the integration of educational technology in the University of Southern Queensland in Australia. It describes the process of converting existing print-based distance education material to technology mediated e-learning formats. The main findings revealed that there are three main concerns: the institutional barriers, the individual inhibitors and the pedagogical concerns. The first one is mainly due to the lack of top management commitment, of system reliability including technological problems such as slow download., a lack of technical support in both use of technology and its integration in the curriculum and also a lack of trainings on how to develop e-learning formats. The second concern is centered on the academic workload to develop, implement and maintain a courseware. The third concern focuses on cognitive overload which can result from multiple representations of content. Since low completion rates are the major issue with the online experience, many universities decided to embed MOOCs by assigning credit to partial or full completion for an attempt to retain students. Some examples of blended learning have proved to have positive impact on students' learning experience. The University of Zaghreb, in the faculty of Organization and Informatics in Croatia, a similar experience was conducted and questionnaires with open ended questions from a diary students were asked to keep regularly revealed that blended learning contributes significantly to increasing knowledge retention provided by regular assessment and quizzes throughout the course, generally students claimed their workload didn't fit within their schedule and language has been pointed out as an obstacle for many students as 
well as prior knowledge about the topic despite the course description that declared no specific knowledge requirements to take the course[24]. Caulfield et al. [25]used standford's introduction to databases in a course for a group of 26 students at the university of Puerto Rico Rio Piedras in Puerto Rico. The MOOC fit the on-campus computer science class at the University. During free time, the teacher did in-class activities projects and evaluation based on content from the MOOC. The data collected from discussion forums revealed very little interaction between students. The study also concluded that the time students spent on study material increased. Bruff et al. [26]integrated the Stanford's University machine learning MOOC at Vanderbilt University. 10students were concerned. The MOOC was adopted integrally, students watched video lectures, discussions forums, completed quizzes and projects assignments. They were asked to send screenshots of their work to the on-campus instructor. The experience revealed that students were very satisfied with the experience, they reported the MOOC to very convenient, flexible, customizable and accessible. Again, poor participation was reported, students preferred local community interaction to discussion forums, even though these were very useful to get help from other students. They also declared that the teacher's role as a facilitator in face to face settings was very important.

Table 2. Benefits and drawbacks of moocs integration in academic contexts

\begin{tabular}{|l|l|}
\hline \multicolumn{1}{|c|}{ Benefits } & \multicolumn{1}{c|}{ Drawbacks } \\
\hline Convenience, flexibility, accessibility & Lack of top management control \\
Increasing success rates & Academic workload to create, implement and \\
Increasing students' retention & maintain a courseware \\
Popularizing difficult course: Challenging & Technological illiteracy \\
courses are approachable & Technological infrastructure deficiency: internet \\
Empowering students' engagement & bandwidth \\
Increasing time spent on course material & $\begin{array}{l}\text { Course design requirements and students' knowledge } \\
\text { mismatch }\end{array}$ \\
& Little interaction with peers and instructor \\
& \\
& \\
\hline
\end{tabular}

\section{A blended Learning Implementation Approach for the Academic Context}

In light of the above, our work consists of proposing a blended learning implementation approach that takes into consideration all the hindrances mentioned earlier so as to cater for the drawbacks and take the most of the benefits MOOCs implementation presents in Academic contexts.

\subsection{Existing e-learning framework}

The e-learning Planning Framework (eLPF) is an online framework providing help to schools and teachers to assess e-learning capability for digital learning 
commitment. The framework considers five factors to respect thoroughly in order for institutions to preserve their e-capability development. Leadership and strategic directions are about the strategic planning and the vision of the school, Learning and teaching includes curriculum, pedagogy and evaluation, professional learning includes learning groups and inquiries, Technological and infrastructure encompasses the technological and technical dimension. The fifth dimension, beyond the classroom, suggests ways that schools can promote digital learning through community. The Khan's framework has eight dimensions: the institutional deals with administrative issues such as leading organization and change, accreditation, budgeting, the pedagogical dimension concerns teaching according to established goals and objectives, content and approach design, methods and various learning strategies and activities, the technological factor reflects on issues pertaining to technology infrastructure, hardware and software. The interface design looks at the site design and usability. The evaluation refers to assessment of learners and of the learning environment. The management includes the maintenance of the learning environment. The resource support relates to online support such as instructors, technicians, and other resources implied in the learning environment and the ethical which examines diversities and legal issues such as privacy, plagiarism and copyright[27].

All these frameworks provide some effective guidance for institutions to embrace blended learning, but still don't take into account all the stakeholders of the blended learning experience, further more these are mainly e-learning frameworks and don't take into consideration the hybrid aspect of learning which consists of a blending of face to face learning and online learning. For this purpose, we have decided to base our model on Khan's framework in order to give new impetus to online education in Academic contexts. Khan's theoretical e-learning model framework is known to be more exhaustive, it is important to note that this is not an attempt to evaluate the framework but to highlight issues that need to be addressed in order to implement a successful learning experience. In our study we sought to match the issues pertaining to MOOCs implementation in the Academic context that we have exposed in the literature to the different dimensions on the Khan's framework. The figure 1 presents the transcription of blended learning related issues. 


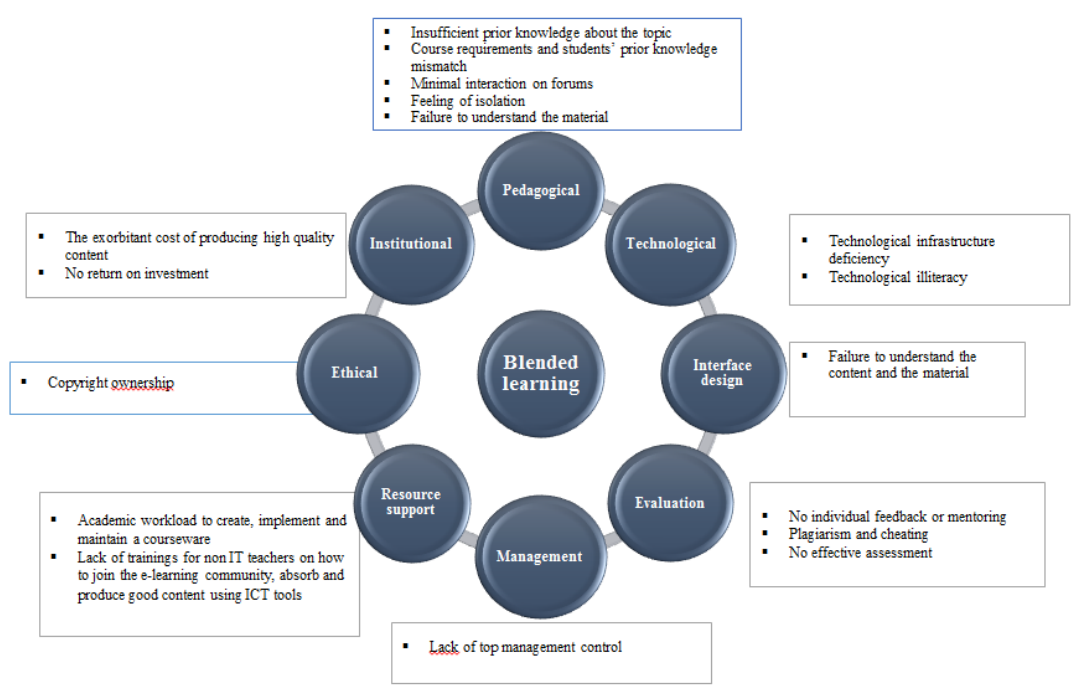

Fig. 1. Transcription of Blended learning challenges on Khan's framework

Based on the illustration above, we tried to propose 6 steps guided approach to ensure a smooth transition to a successful blended learning implementation. The approach is illustrated in figure 2 .

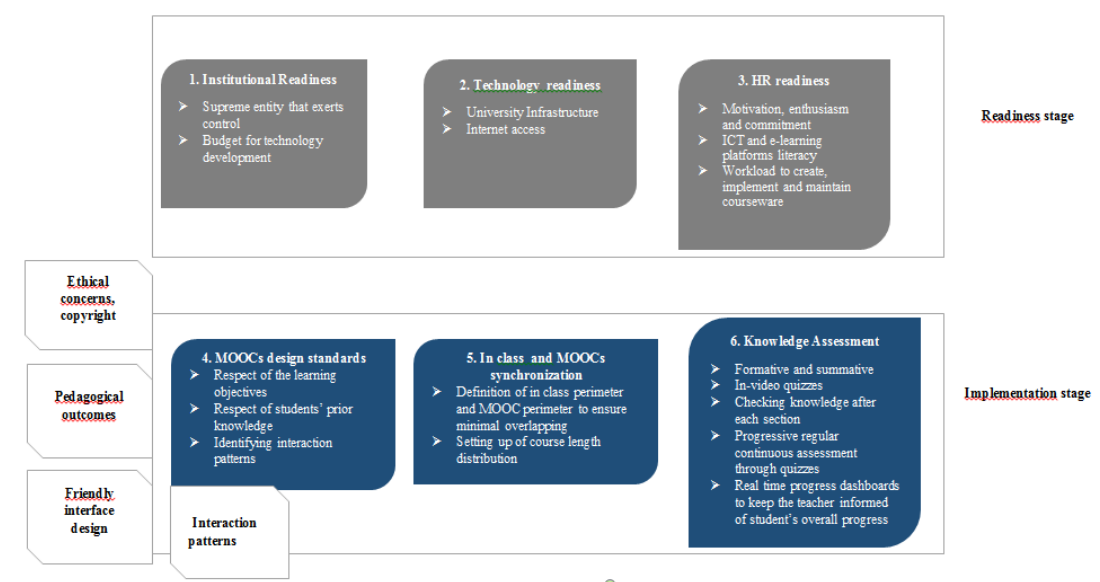

Fig. 2. A 6 steps approach for blended learning implementation in Academic contexts

The proposed approach in figure 2 breaks down into 2 main stages: the readiness stage and the implementation stage. The readiness stage encompasses three fundamental steps which are: 


\subsection{Institutional readiness}

The institutional readiness implies the existence of a top management ruling entity that oversees the whole implementation process. Since such implementations require huge sums of money, a budget should be dedicated to the development of the consequent technology. Fischbacher-Smith [28] explains the reasons behind stating that effective organizational change management should lie on organizational commitment. Only with a devoted entity that manages, oversees and controls the deployment of blended learning in higher education can we keep track of the implementation process and guarantee its monitoring until it is well achieved.

\subsection{Technological readiness}

The university infrastructure should be able to bear the implementation of blended learning. Access to the internet should be provided to all students enrolled in universities.

\subsection{Human Resources readiness}

Teachers should be given trainings on how to convert their courses into MOOCs and to work with a platform. On the other hand, the workload of teachers should allow for creation, implementation and maintenance time, because these are time consuming. Teachers should benefit from specific hands on trainings upstream of blended learning integration. Timetables and schedules should be adjusted to take into consideration the developmental phase of MOOCs and their integration.

Besides, our implementation stage, in his turn, considers three main sub stages which are:

\subsection{MOOCS design standards}

For every course, a given MOOC integration should undergo the following process:

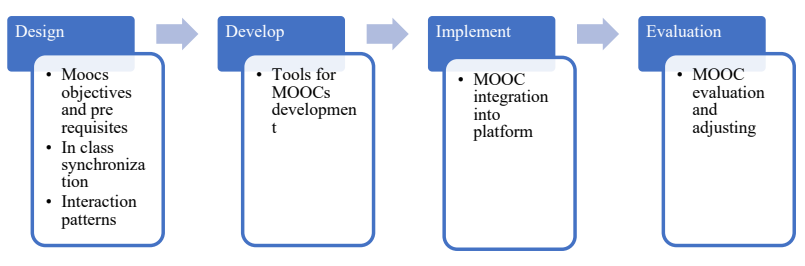

Fig. 3. MOOC implementation process 
The choice of MOOCs should respect copyright ownership, as well as the learning objectives of the course. MOOCs content should align with student's prior knowledge. Interaction patterns should be defined in online settings for each task so as to encourage peer to peer interaction on forums as well as instructor to student interaction.

During this phase, it is very important to consider some factors such as Ethical problems pertaining to copyright conflicts, to state pedagogical outcomes, and make sure the interface delivery and the sequencing of chapters is user friendly. Another point which is extremely important is the structure, the pace and the length. Another element to consider during the design phase is the need of students to interact and make requests about different aspects in MOOCs. Recent studies recognized that the number of students per lecturer in blended learning environments has risen and thus has made individualized support impossible [29]. This problem can be solved through chatbots to make individualized support possible and gather students who are not able to engage effectively in the platform. A chatbot is a conversional agent that interacts with users through natural language. Chatbots can be grafted to the discussions Forum so as to provide feedback on common problems or to support students who block with problems that keep coming back or students who have difficulties to apply concepts learned in class.

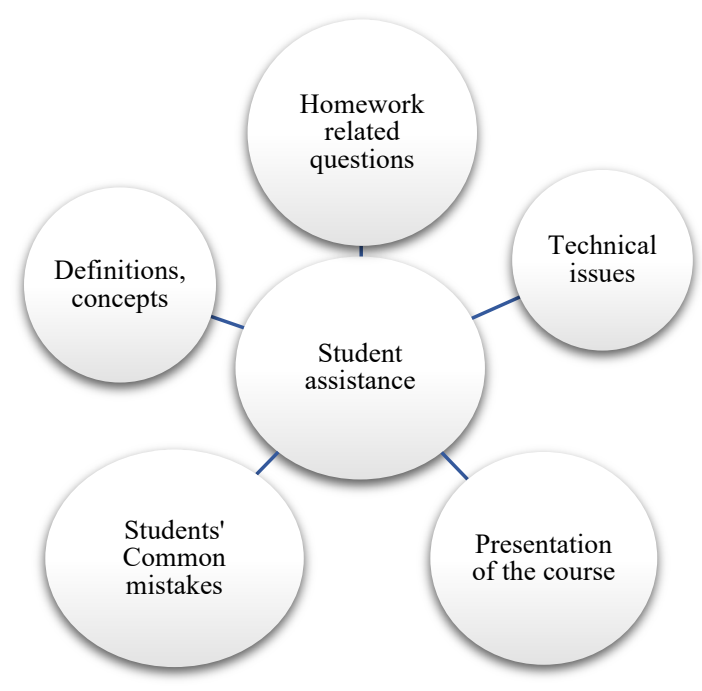

Fig. 4. Students assistance in blended learning environments

Furthermore, the MOOC should allow for many activities to suit different learning styles, including hands on approach to problems, technical tasks, abstract concepts and ideas. At the beginning, the learning style can be obtained through questionnaires as well as learner's behavior in order to determine the learner's model and recommend appropriate resources for each learning profile.[30] 


\subsection{In class and MOOCs content synchronization}

When designing MOOCs, teachers should think of defining the objective of the MOOC in order to prevent unnecessary overlapping with in class content. When deemed useful, face to face and online content can be redundant in order to foster knowledge retention as for very difficult courses.

\subsection{Knowledge assessment}

Continuous assessment should be the rule to prevent weak students from lagging behind. Online quizzes with dashboards and key indicators to keep the instructor informed of students' overall progress should be implemented. According to K. F. Hew, C. Qiao, and Y. Tang study [15], in order to avoid student mind wandering, videos should embed short recall quizzes. Another key element that springs to mind about assessment is cheating and plagiarism. Previous studies attempted to implement an E-exam cheating detection system [31] to prevent students from cheating and give credibility to e-assessment. They suggested a solution of an online proctor whose role is to detect any cheating activities during exams through a combination of fingerprint continuous authentication and eye tracking. In a similar study, Okada et al. [32] conducted a study involving seven universities across Europe to , the outcomes support the use of innovative technology in assessment.

\section{$5 \quad$ Future Work}

Our study tried to put forward the problems that emerged in the field of online learning since the apparition of MOOCs, it was also an investigation into barriers impeding positive blended learning experiences from different universities in the world, illustrated through the Khan's framework 8 dimensions, our findings from the literature review summary echo the 8 dimensions of Khan's framework. It is clear that any institution that has the intention to integrate MOOCs in traditional settings will have to go through a series of steps to enable a successful transition. An approach comprising 6 main steps has been developed to guide universities, our next objective is to try to implement this approach with possible solutions extensions which will be subject to subsequent tests in the Academic context.

\section{Bibliography}

[1] E. Costello, J. Brunton, M. Brown, and L. Daly, "In MOOCs we Trust: Learner Perceptions of MOOC Quality via Trust and Credibility," Int. J. Emerg. Technol. Learn. IJET, vol. 13, no. 06, p. 214, May 2018, https://doi.org/10.3991/ijet.v13i06.8447.

[2] M. Giannakos, L. Jaccheri, and J. Krogstie, "Looking at MOOCs Rapid Growth Through the Lens of Video-Based Learning Research,” Int. J. Emerg. Technol. Learn. IJET, vol. 9, no. 1, p. 35, Feb. 2014, https://doi.org/10.3991/ijet.v9i1.3349. 
[3] D. D. Manar, "MOOCs in Moroccan Higher Education: Rationale, Implementation and Challenges," vol. 2, no. 2, p. 3, 2016.

[4] M. Sahami and M. Guzdial, "The Revolution Will Be Televised: Perspectives on Massive Open Online Education," p. 2.

[5] S. M. North, R. Richardson, and M. M. North, "To Adapt MOOCS, or Not? That is No Longer the Question," p. 4.

[6] S. Zheng, M. B. Rosson, P. C. Shih, and J. M. Carroll, "Understanding Student Motivation, Behaviors and Perceptions in MOOCs," in Proceedings of the 18th ACM Conference on Computer Supported Cooperative Work \& Social Computing - CSCW '15, Vancouver, BC, Canada, 2015, pp. 1882-1895, https://doi.org/10.1145/2675133.2675217.

[7] J. W. H. Sit, J. W. Y. Chung, M. C. M. Chow, and T. K. S. Wong, "Experiences of online learning: students' perspective," Nurse Educ. Today, vol. 25, no. 2, pp. 140-147, Feb. 2005, https://doi.org/10.1016/j.nedt.2004.11.004.

[8] D. C. Schmidt and Z. McCormick, "Producing and delivering a coursera MOOC on pattern-oriented software architecture for concurrent and networked software," in Proceedings of the 2013 companion publication for conference on Systems, programming, \& applications: software for humanity - SPLASH '13, Indianapolis, Indiana, USA, 2013, pp. 167-176, https://doi.org/10.1145/2508075.2508465.

[9] R. McGreal, W. Kinuthia, S. Marshall, Commonwealth of Learning, and Athabasca University, Open educational resources: innovation, research and practice. 2013.

[10] Y. Chen, "Investigating MOOCs through blog mining," Int. Rev. Res. Open Distrib. Learn., vol. 15, no. 2, Apr. 2014, doi: 10.19173/irrodl.v15i2.1695.

[11] "K. Yee and P. MacKown ," Detecting and preventing cheating duringexams," PEDAGOGY, NOT POLICING, p.141 , 2009."

[12] J. Sinclair, R. Boyatt, C. Rocks, and M. Joy, "Massive open online courses: a review of usage and evaluation,” Int. J. Learn. Technol., vol. 10, no. 1, p. 71, 2015, https://doi.org/ 10.1504/ijlt.2015.069450

[13] K. F. Hew and W. S. Cheung, "Students' and instructors' use of massive open online courses (MOOCs): Motivations and challenges," Educ. Res. Rev., vol. 12, pp. 45-58, Jun. 2014, https://doi.org/10.1016/j.edurev.2014.05.001.

[14] "Romero et Ventura - 2017 - Educational data science in massive open online co.pdf." .

[15] K. F. Hew, C. Qiao, and Y. Tang, "Understanding Student Engagement in Large-Scale Open Online Courses: A Machine Learning Facilitated Analysis of Student's Reflections in 18 Highly Rated MOOCs," Int. Rev. Res. Open Distrib. Learn., vol. 19, no. 3, Jul. 2018, https://doi.org/10.19173/irrodl.v19i3.3596.

[16] "Felder, RM., How students learn: Adapting teaching styles to learning styles, Frontiers in Education ConferenceProceedin." https://doi.org/10.1109/fie.1988.35029.

[17] "Kolb, A., and Kolb, D.A., Kolb's learning styles, Encyclopedia of the Sciences of Learning, NY: Springer US, pp. 1698-17.” https://doi.org/10.1007/978-1-4419-1428$\underline{6} 228$.

[18] J. Xi, Y. Chen, and G. Wang, "Design of a Personalized Massive Open Online Course Platform,” Int. J. Emerg. Technol. Learn. IJET, vol. 13, no. 04, p. 58, Mar. 2018, https:// doi.org/10.3991/ijet.v13i04.8470

[19] D. R. Garrison and H. Kanuka, "Blended learning: Uncovering its transformative potential in higher education," Internet High. Educ., vol. 7, no. 2, pp. 95-105, Apr. 2004, https://doi.org/10.1016/j.iheduc.2004.02.001.

[20] R. J. Griffiths, M. M. Chingos, R. Spies, and C. Mulhern, "Adopting MOOCs on Campus: A Collaborative Effort to Test MOOCs on Campuses of the University System of 
Maryland," Online Learn., vol. 19, no. 2, Dec. 2014, https://doi.org/10.24059/olj.v19i2.52 3.

[21] K. Ghadiri, P. Hsu, and S. Sujitparapitaya, "The Transformative Potential of Blended Learning Using MIT edX’s 6.002x Online MOOC Content Combined with Student TeamBased Learning in Class," p. 15.

[22] P. Chatterjee and A. Nath, "Massive open online courses (MOOCs) in education \&\#x2014; A case study in Indian context and vision to ubiquitous learning," in 2014 IEEE International Conference on MOOC, Innovation and Technology in Education (MITE), Patiala, India, 2014, pp. 36-41, https://doi.org/10.1109/mite.2014.7020237.

[23] D. Birch and B. Burnett, "Bringing academics on board: Encouraging institution-wide diffusion of e-learning environments," Australas. J. Educ. Technol., vol. 25, no. 1, Feb. 2009, https://doi.org/10.14742/ajet.1184.

[24] A. Bralić and B. Divjak, "Use of MOOCs in Traditional Classroom: Blended Learning Approach,” Eur. J. Open Distance E-Learn., vol. 21, no. 1, Feb. 2018.

[25] "Rethinking Online Community in MOOCs Used for Blended Learning." [Online]. Available: https://er.educause.edu/articles/2013/10/rethinking-online-community-inmoocs-used-for-blended-learning. [Accessed: 23-Aug-2019].

[26] D. Bruff, D. Fisher, K. McEwen, and B. Smith, "Wrapping a MOOC: Student perceptions of an experiment in blended learning," p. 20.

[27] B. Khan, Managing E-Learning Strategies: Design, Delivery, Implementation and Evaluation. IGI Global, 2005.

[28] J. Adekola, V. H. M. Dale, K. Gardiner, and M. Fischbacher-Smith, "Student Transitions to Blended Learning: An Institutional Case Study,” J. Perspect. Appl. Acad. Pract., vol. 5, no. 2, Mar. 2017, https://doi.org/10.14297/jpaap.v5i2.273.

[29] "Brinton, C. G., Rill, R., Ha, S., Chiang, M., Smith, R., \& Ju, W. 2015. Individualization forEducation at Scale: MIIC De." https://doi.org/10.1109/tlt.2014.2370635.

[30] B. Hmedna, A. E. Mezouary, O. Baz, and D. Mammass, "Identifying and tracking learning styles in MOOCs: A neural networks approach," vol. 19, no. 2, p. 9, 2017. https://doi.org/ $10.1109 /$ icmcs.2016.7905606

[31] R. Bawarith, Dr. Abdullah, Dr. Anas, and Prof. Dr., "E-exam Cheating Detection System," Int. J. Adv. Comput. Sci. Appl., vol. 8, no. 4, 2017, https://doi.org/10.14569/ijacsa.2017.08 0425.

[32] A. Okada, D. Whitelock, W. Holmes, and C. Edwards, "e-Authentication for online assessment: A mixed-method study: e-Authentication for online assessment," Br. J. Educ. Technol., vol. 50, no. 2, pp. 861-875, Mar. 2019, https://doi.org/10.1111/bjet.12608

\section{$7 \quad$ Authors}

Aicha Marrhich received the Engineering degree in Computer Science from Ecole Mohammadia des Ingénieurs, Rabat, Morocco in 2011. Her research interests include e-learning, artificial intelligence applied to the education realm.

Ichrak Lafram received his Engineering degree in Computer Science from the Institut National des Statistiques et des Sciences Appliquées, Rabat Morocco in 2010. His research interests include big data and artificial intelligence, machine learning, neural networks. 
Naouale Berbiche is a research director at Lab. of Systems Analysis, Information Processing and Integrated Management. Her interests include artificial neural networks, e-learning in higher education, UML models.

Jamila El Alami is a research director at Lab. of Systems Analysis, Information Processing and Integrated Management. She is also the head of the Scientific and technical affairs Department at The National Centre for Scientific and Technical Research in Morocco. Her interests include machine learning, blended learning experience.

Article submitted 2019-12-30. Resubmitted 2020-03-03. Final acceptance 2020-03-04. Final version published as submitted by the authors. 